2001 Number 2

18 July 2001

\title{
VOCALIZATION OF THE CROCODILE SKINK, TRIBOLONOTUS GRACILIS (DE ROOY, 1909), AND EVIDENCE OF PARENTAL CARE.
}

Ruston W. Hartdegen'1, Matthew J. Russell'2, Bruce Young³, and Richard D. Reams ${ }^{1}$

${ }^{1}$ Dallas Zoo, Department of Herpetology, 650 South R.L. Thornton Freeway, Dallas, Texas, 75203, ruston17@yahoo.com

2918 N. Elm, Denton, TX 76201

${ }^{3}$ Lafayette College, Department of Biology, Easton, Pennsylvania 18042-1778.

The crocodile or spiny skinks, Tribolonotus, comprise eight secretive semi-fossorial lizards, which are generally found under vegetation in the immediate vicinity of water (Greer and Parker, 1968; O'Shea, 1991, 1994; Rogner, 1997). Tribolonotus gracilis (Figure 1) and Tribolonotus novaeguineae are restricted to New Guinea, while the remaining six species range throughout Indonesia, Manus, New Britain, Bougainville, and the Solomon Islands (McCoy, 1980; O'Shea, 1991, 1994). Because scant life history information is available for the genus Tribolonotus, the purpose of the present contribution is to document the vocalization and parental care of $T$. gracilis.

Lacertilian vocalization is well known, particularly within the Gekkonidae and Pygopodidae (e.g., Marcellini, 1978; Böhme et al., 1985; Greer, 1989), where sound production is often associated with laryngeal specialization (Russell et al., 2000). Little is known with respect to the behavioral context of these calls and their role in lizard social dynamics. Differences in vocalizations are thought to reflect different social functions, some of which are sex dependent. Regardless of their differences, vocalizations generally fall into one of two categorizes, either advertisement or distress. Although clear structural differences between male and female vocalizations and their functional roles have been identified for a handful of gecko species (Frankenberg and Werner, 1992; Marcellini, 1978) much remains unknown, particularly outside of the family Gekkonidae. Greer (1989) lists several scincid lizards reported to vocalize during physical manipulation or aggressive encounters. Similarly, defensive sound production has been reported from wild and captive specimens of $T$. gracilis (O'Shea, 1991, 1994; Russell, 1996; Rogner, 1997), but no acoustic analyses of these sounds have been performed. Preliminary observations of captive $T$. gracilis suggests their behavioral repertoire 
includes a defensive vocal response to potential egg predation or danger (personal observation).

We are unaware of other reports of squamate vocal behavior in relation to egg defense or parental care. While the nature and extent of squamate parental care can be highly variable, members of the family Scincidae have commonly been reported to display behaviors ranging from egg brooding, nest guarding, and offspring protection. Eumeces fasciatus has been documented to engage in a series of complex nesting behaviors including regulation of nest temperature by adjusting egg depth, moving eggs from flooded burrows, urinating within the nest to maintain moisture, turning eggs to prevent molding, and ingestion of spoiled eggs (see Shine, 1988, for review). Herein, we describe observations which may provide evidence of parental care from an additional member of the family Scincidae, $T$. gracilis.

\section{METHODS}

\section{Vocalizations}

Recordings of defensive vocalizations were taken from a pair of wild-collected adult $T$. gracilis purchased from Glades Herp (Fort Myers, Florida) and maintained at the author's (MJR) residence. The male had a snout vent length (SVL) of $102.6 \mathrm{~mm}$, a total length (TL) of $194.7 \mathrm{~mm}$, and a mass of $63.4 \mathrm{~g}$. The female had a SVL of $94.6 \mathrm{~mm}$, a TL of $184.3 \mathrm{~mm}$, and a weight of $47.7 \mathrm{~g}$. Vocalizations were elicited by holding each animal in the palm of one hand while gently running one finger along the lizard's dorsum. Lizard vocalizations were recorded with an Optimus CTR-108 cassette recorder. Recordings were transferred to an Apple G4 computer (sampling rate $=44.1 \mathrm{kHz}$ ) using an InstruNet A/D converter and data acquisition system (G.W. Instruments). Soundscope software (G.W. Instruments) was used to generate sonograms and power spectral analyses (Fast Fourier transformation using 2048 points and a $59 \mathrm{~Hz}$ filter) of each call.

\section{Observations}

Three pair of adult wild-collected T. gracilis were purchased from Bushmaster Reptiles Inc. (Boulder, CO) and maintained at the Dallas Zoo Department of Herpetology. Enclosure design and husbandry parameters were previously reported in Russell (1996). Male mean measurements were as follows: SVL of $101.2 \mathrm{~mm}(\mathrm{sd}=3.7 \mathrm{~mm})$, TL of $190.0 \mathrm{~mm}(\mathrm{sd}=5.3 \mathrm{~mm})$, and mass of $62.7 \mathrm{~g}$ $(\mathrm{sd}=4.5 \mathrm{~g})$. Mean female measurements were: $\mathrm{SVL}$ of $97.5 \mathrm{~mm}$ ( $\mathrm{sd}=3.3$ $\mathrm{mm})$, TL of $185.8 \mathrm{~mm}(\mathrm{sd}=4.0 \mathrm{~mm})$, and a mass of $49.3 \mathrm{~g}(\mathrm{sd}=6.2)$. Between 12 October, 1999, and 24 February, 2000, three female $T$. gracilis deposited single eggs, which were left to incubate in their respective 
nesting site. Eggs were deposited on a sphagnum moss substrate under a $10.16 \mathrm{~cm} 2$ piece of cork bark. Each enclosure housed an adult pair and their egg. The cork bark was removed daily for five consecutive days per week for the duration of incubation (approximately 60 days) to check the positioning of the females and their eggs. Twice a month, each egg was gently touched to test lizard responses. On twelve separate occasions after the cork bark had been removed from the nesting areas, the eggs were left uncovered and rechecked the following day. After all three eggs hatched, two of the neonates were left with their parents for a period of two weeks. The position of each neonate in proximity to its parents was checked daily.

\section{RESULTS}

\section{Vocalizations}

Given the relative scarcity of these animals, the absence of previous quantitative descriptions of their vocalizations (Audio 1), and the level of variation observed in the quantitative features of the sounds, we have treated each call as an independent event for the purposes of statistical analysis. The calls produced by the male had a longer duration $(x=0.14 \mathrm{sec}, \mathrm{sd}=0.006$ ) than those of the female $(x=0.11 \mathrm{sec}, \mathrm{sd}=0.003)$ (Figure 2), a difference that is significant despite the small sample size $(t=3.35, d f=3, p=0.044)$. Variation within the structure of the vocalizations between the sexes was evident. Although calls of both sexes were pulsatile, the female call had a much slower pulse rate $(500 \mathrm{~Hz})$ than the male $(775 \mathrm{~Hz})$ (Figure 3). In both sexes, the pulse rate of the calls slowed near the end of the vocalization. Little amplitude modulation or temporal patterning was found.

Sonogram analyses indicated calls of both sexes (Figure 3 ) share a similar overall frequency range $(500-10,000 \mathrm{~Hz})$, although the call of the male had a slightly higher frequency range. In both sexes, vocalizations were initiated and terminated by "noisy" segments, characterized by broad-band sounds. The middle of each call was composed of relatively clean harmonics. There were minor frequency shifts (approximately $100 \mathrm{~Hz}$ ) in both calls. Visual comparison of the overtone pattern within each call indicates the presence of more harmonics in the female's vocalization.

Power spectral analyses of the calls from both sexes clearly confirmed the presence of harmonics in both calls and the difference in the harmonic signatures. In the male the fundamental frequency was approximately $830 \mathrm{~Hz}$ (Figure 4), while the fundamental frequency of the female's call was closer to $420 \mathrm{~Hz}$ (Figure 4). In both sexes, every harmonic was present, although some dropped out over $9000 \mathrm{~Hz}$. 


\section{Observations on Parental Care}

During all daily observation periods the females were found curled around their egg. Whenever eggs were gently handled by the observer the female exhibited defensive open-mouth lunges. During approximately $50 \%$ of trials this female defensive display included vocalization. To the observers these calls superficially sounded similar to those produced by $T$. gracilis when handled, but no recordings or analyses were conducted. In all twelve cases when eggs were left uncovered, on the subsequent day they were found reburied. Although this behavior was not directly observed, we assume females were responsible for covering eggs, as we found no prior evidence of male defensive behavior or protection of eggs or young. During the two-week period of observation after eggs hatched, both neonates were found to stay near their mother (within $2 \mathrm{~cm}$ ) and on several occasions they were found resting on the female's dorsum. Although males were occasionally within $2 \mathrm{~cm}$ of neonates, there was no evidence of males consistently present in close proximity to neonates. Males did not appear to display any aggression toward either their young or to the authors' disturbance of eggs.

\section{DISCUSSION}

Although the exact role of $T$. gracilis vocalization is unknown, it is assumed to play a defensive role, which may be associated with parental care. While we did analyze the distress calls of manipulated male and female lizards, we did not examine the female vocalizations elicited by egg disturbance. In spite of this fact, our observations provide evidence of previously undocumented saurian parental care. Females emitted vocalizations in the presence of a potential threat to their eggs. These observations may provide a glimpse into the functional role of vocalization in $T$. gracilis social dynamics. The role of vocalization in offspring defense appears more evident in light of reports that $T$. gracilis, and other species within this genus, are most often collected in pairs or trios consisting of one male and one or two females (Greer and Parker, 1968; O'Shea, 1994). These reports suggest Tribolonotus to be relatively social lizards within small groups. Such situations seem conducive to the existence of parental care. Observations of captive lizards support this notion as well; males did not act aggressively toward young and females remained in close proximity to their neonates for some duration. Our observations provide evidence of female parental care in $T$. gracilis, including egg brooding, nest guarding, offspring defense including vocalization, as well as social associations between parents and offspring.

The acoustic properties of the vocalizations and behavioral context of calls elicited both by restraint and by attempted egg disturbance, all suggest that 
these defensive sounds are produced by an exhalatory airflow. The harmonic structure of the sounds suggest that there are may be anatomical specializations within the larynx (e.g., Rittenhouse et al., 1998). Our results suggest that there may be acoustic sexual dimorphism in the defensive sounds produced by $T$. gracilis. The acoustic dimorphism does not appear to be size related (in that the larger males produced higher frequency sounds) and thus may reflect sexual dimorphism within the larynx or trachea (Young, 2000).

The sounds produced by both male and female lizards during manipulation seemed superficially similar to those produced by females during egg guarding episodes. Based on past studies of lizard sound production, it is possible that these two situations (i.e., lizard manipulation and egg guarding) elicit distinctively different calls and such calls differ both structurally and functionally. Suggestions for future vocalization research with $T$. gracilis would include examining possible vocal responses during intra-specific encounters and sound analysis of these vocalizations, as well as those produced by female during egg protection.

\section{ACKNOWLEDGMENTS}

We thank the following people for their comments on earlier drafts of this manuscript: C. Bennett, J. Boylan, J. Russell, and the staff of the Dallas Zoo Department of Herpetology. Thanks to D. T. Roberts for providing photographic support.

BÖHME, W., R. HUTTERER AND W. BINGS.

\section{LITERATURE CITED}

1985. Die Stimme der Lacertidae, speziell der Kanareneidechsen (Reptilia: Sauria). Bonner Zoologische Beiträge 36: 337-354.

FRANKENBERG, E. AND Y. L. WERNER. 1992. Vocal communication in the reptilia-facts and questions. Acta Zool. Lilloana 41: 45-62.

GREER, A. E.

1989. The Biology and Evolution of Australian Lizards. Chipping Norton, NSW Australia: Surrey Beatty \& Sons Pty Limited.

GREER, A. E. AND F. PARKER. 1968. A new species of Tribolonotus (Lacertilia:Scincidae) from Bougainville and Buka, Solomon Islands, with comments on the biology of the genus. Breviora 291: 1-23. 
MARCELLINI, D. L.

1978. The acoustic behavior of lizards. Pages 287-300. In Behavior and

Neurology of Lizards (N. Greenberg and P. D. MacLean, eds.). National Institute of Mental Health, Rockville, Maryland.

MCCOY, M.

1980. Reptiles of the Solomon Islands. Wau Ecology Institute. Wau, Papua New Guinea.

O'SHEA, M.

1991. Reptiles of Papua New Guinea. British Herpetological Society Bulletin 37:

15-17.

1994. The herpetofauna of coconut husk piles on Kar Kar Island, Madang

Province, Papua New Guinea. ASRA Journal. 51-72.

RITTENHOUSE, D.R., A.P. RUSSELL, AND A.M. BAUER.

1998. The larynx and trachea of the barking gecko, Ptenopus garrulus

maculatus (Reptilia: Gekkonidae) and their relation to vocalization. South African Journal of Zoology 33: 23-30.

ROGNER, M.

1997. Lizards, Vol. 2. Krieger, Malabar, Florida.

RUSSELL, A.P., D.R. RITTENHOUSE, AND A.M. BAUER.

2000. Laryngotracheal morphology of the Afro-Madagascar geckos: A

comparative survey. Journal of Morphology 245: 241-268.

RUSSELL, M. J.

1996. Notes on the natural history, captive husbandry, and reproduction of the Crocodile skinks (Tribolonotus gracilis) at the Dallas Zoo. Pp. 69-74 In Advances in Herpetoculture. P. Strimple (eds.). International Herpetological Symposium, Inc.

SHINE, R.

1988. Parental care in reptiles. Pp. 275-329 In Biology of the Reptilia, Volume 16, Ecology B, Defense and Life History. Gans, C. and R. B. Huey (eds.). Alan R. Liss Inc., New York.

YOUNG, B.A.

2000. The comparative morphology of the ophidian larynx. Acta Zool. 81: 177193. 